\title{
Robust Nonlinear Flight Control of a High-Performance Aircraft
}

\author{
Qian Wang, Member, IEEE, and Robert F. Stengel, Fellow, IEEE
}

\begin{abstract}
This paper considers probabilistic robust control of nonlinear uncertain systems. A combination of stochastic robustness and dynamic inversion is proposed for general systems that have a feedback-linearizable nominal system. In this paper, the stochastic robust nonlinear control approach is applied to a highly nonlinear complex aircraft model, the high-incidence research model (HIRM). The model addresses a high-angle-of-attack enhanced manual control problem. The aim of the flight control system is to give good handling qualities across the specified flight envelope without the use of gain scheduling and also to provide robustness to modeling uncertainties. The proposed stochastic robust nonlinear control explores the direct design of nonlinear flight control logic. Therefore, the final design accounts for all significant nonlinearities in the aircraft's high-fidelity simulation model. The controller parameters are designed to minimize the probability of violating design specifications, which provides the design with good robustness in stability and performance subject to modeling uncertainties. The present design compares favorably with earlier controllers that were generated for a benchmark design competition.
\end{abstract}

Index Terms-Monte Carlo simulation, nonlinear control, randomized algorithms, stochastic robustness.

\section{INTRODUCTION}

$\mathbf{O}$ NE OF THE major problems in the design of flight control systems is modeling uncertainties and parameter variations in characterizing an aircraft and its operating environment. While many gains have been made in robust control theory over the past several decades, the gap between the new methods and conventional flight control design approaches has precluded their widespread use. To address this problem, the Group for Aeronautical Research and Technology in Europe (GARTEUR) proposed two benchmark problems for robust flight control design: an automatic landing control problem and a high angle of attack enhanced manual control problem [1]. The objectives for these benchmarks were to demonstrate how robust flight control theory could be applied to realistic problems, to identify the limitations of existing techniques, and to raise the awareness and confidence of the aeronautical industry in the use of robust control techniques [1].

Manuscript received April 25, 2003; revised February 25, 2004. Manuscript received in final form March 30, 2004. Recommended by Associate Editor S. Kim. This work was supported by the Federal Aviation Administration and the National Aeronautics and Space Administration under FAA Grant 95-G-011.

Q. Wang is with the College of Engineering, Department of Mechanical Engineering, The Pennsylvania State University, University Park, PA 16802 USA (e-mail: quw6@psu.edu).

R. F. Stengel is with Princeton University, Princeton, NJ 08544 USA (e-mail: stengel@ princeton.edu).

Digital Object Identifier 10.1109/TCST.2004.833651
The high-incidence research model (HIRM) problem, which is addressed in this paper, is based on a military aircraft configuration. The flight envelope contains a wide range of angles of attack and sideslip $\left(50^{\circ}\right.$ to $120^{\circ}$ for angle of attack, and $-50^{\circ}$ to $50^{\circ}$ for sideslip angle). Traditionally, flight control laws for low- to moderate angle-of-attack flight have been designed using linear design methods on linearized aircraft models. Gain scheduling is necessary for these control laws to guarantee stability and performance at extreme flight conditions. The control laws must be designed at many operating points, and a great amount of assessment is required to ensure adequate stability and performance at off-design points. An alternative approach is to explore direct techniques for designing nonlinear control systems, such as dynamic inversion [2]-[9].

In addressing robustness issues with respect to parameter variations for a given dynamic model, deterministic worst-case approaches to designing robust controllers are aimed at guaranteed satisfaction of specifications for worst-case uncertainties. These approaches could suffer from significant conservatism and computational complexity (as the problem is NP hard). Alternatively, stochastic robustness analysis and design (SRAD) [10]-[20] is aimed at breaking these computational barriers using algorithms with polynomial complexity to characterize system robustness and to identify satisfactory controllers. Furthermore, in traditional worst-case deterministic robust control theories, it is often necessary to transform the real engineering analysis/design problem to fit the design framework. Stochastic robust control design takes into account the engineering design requirements directly during the design phase, and it minimizes the likelihood that the design metrics are not satisfied. These advantages make the research on stochastic approaches a logical alternative in robust control. The stochastic robust control design has been applied to linear-quadratic-Gaussian regulators [11], [17], transfer function sweep designs [12], and linear-parameter-varying systems [19]. In [13], for the longitudinal motion of a hypersonic aircraft, the stochastic design approach produces an efficient flight control system that achieves good stability and performance robustness.

In this paper, we design a robust flight control system for the HIRM problem by combining stochastic robustness with nonlinear dynamic inversion, for which the theoretical foundation was built in our earlier paper [14]. In [14], the input-to-state stability of a nonlinear system was considered, and a parameterized feedback linearization (with backstepping if necessary) controller was searched by using genetic algorithms (GAs) to minimize a stochastic robustness cost function. This approach allows all significant nonlinearities in the system model to be considered, and it produces better robustness than can be 
achieved with linear design methods. In the following sections, we present the dynamic model and control design requirements for the HIRM problem, our stochastic robustness metrics and cost function, the design of the robust control system, and evaluation and comparison of our design with other controllers developed for the GARTEUR competition.

\section{High-InCIDENCE RESEARCH Model}

The HIRM aircraft configuration has canard and tailplane control surfaces plus an elongated nose. The mathematical model uses aerodynamic data obtained from wind tunnel and flight tests of an unpowered, scaled drop model. Engine, sensor, and actuator models have been added to the mathematical model to create a representative nonlinear simulation of a twin-engine modern fighter. The aircraft is basically stable both longitudinally and laterally, although there are some combinations of angle of attack and control surface deflections that cause the aircraft to be unstable.

Reference [1] described in detail the six-degree-of-freedom nonlinear HIRM, including nonlinear actuator and sensor models. We first present the dynamic equations of motion for a general aircraft, and then address the aerodynamics for the HIRM problem.

\section{A. Rigid Body Equations of Motion for an Aircraft}

The dynamic equations of motion for an aircraft in a combined wind and body axes are written as follows [21]:

$$
\begin{aligned}
\dot{V} & =\frac{F_{w x}}{m}-g \sin \gamma \\
\dot{\alpha} & =q-\frac{q_{w}}{\cos \beta}-p \cos \alpha \tan \beta-r \sin \alpha \tan \beta \\
\dot{\beta} & =r_{w}+p \sin \alpha-r \cos \alpha \\
\dot{\gamma} & =q_{w} \cos \varphi-r_{w} \sin \varphi \\
\dot{\varphi} & =p_{w}+\left(q_{w} \sin \varphi+r_{w} \cos \varphi\right) \tan \gamma \\
\dot{\psi} & =\frac{\left(q_{w} \sin \varphi+r_{w} \cos \varphi\right)}{\cos \gamma} \\
\dot{q} & =\frac{1}{I_{y y}\left[\mathcal{M}+I_{x z}\left(r^{2}-p^{2}\right)+\left(I_{z z}-I_{x x}\right) r p\right]} \\
{\left[\begin{array}{c}
\dot{p} \\
\dot{r}
\end{array}\right] } & =\left[\begin{array}{cc}
I_{x x} & -I_{x z} \\
-I_{x z} & I_{z z}
\end{array}\right]^{-1}\left[\begin{array}{c}
\mathcal{L}+I_{x z} p q+\left(I_{y y}-I_{z z}\right) q r \\
\mathcal{N}-I_{x z} q r+\left(I_{x x}-I_{y y}\right) p q
\end{array}\right]
\end{aligned}
$$

with

$$
\begin{aligned}
q_{w} & =-\frac{F_{w z}}{m V}-\frac{g}{V} \cos \gamma \cos \varphi \\
r_{w} & =\frac{F_{w y}}{m V}+\frac{g}{V} \cos \gamma \sin \varphi \\
p_{w} & =p \cos \alpha \cos \beta+(q-\dot{\alpha}) \sin \beta+r \sin \alpha \cos \beta \\
{\left[\begin{array}{c}
\mathcal{L} \\
\mathcal{M} \\
\mathcal{N}
\end{array}\right] } & =\left[\begin{array}{c}
\mathcal{L}_{A} \\
\mathcal{M}_{A} \\
\mathcal{N}_{A}
\end{array}\right]+\left[\begin{array}{c}
\mathcal{L}_{T} \\
\mathcal{M}_{T} \\
\mathcal{N}_{T}
\end{array}\right] \\
{\left[\begin{array}{c}
F_{w x} \\
F_{w y} \\
F_{w z}
\end{array}\right] } & =-\left[\begin{array}{c}
D \\
S \\
L
\end{array}\right]+\left[\begin{array}{l}
T_{w x} \\
T_{w y} \\
T_{w z}
\end{array}\right] .
\end{aligned}
$$

$$
\begin{array}{ll}
\text { Here } & \text { flight path velocity; } \\
V & \text { angle of attack; } \\
\alpha & \text { sideslip angle; } \\
\beta & \text { wind-axis Euler angles; } \\
\gamma, \varphi, \psi & \text { body-axis angular rates; } \\
p, q, r & \text { wind-axis angular rates; } \\
p_{w}, q_{w}, r_{w} & \text { body-axis total rolling, pitching, } \\
\mathcal{L}, \mathcal{M}, \mathcal{N} & \text { and yawing moments; } \\
\mathcal{L}_{A}, \mathcal{M}_{A}, \mathcal{N}_{A} & \text { body-axis aerodynamic moments; } \\
\mathcal{L}_{T}, \mathcal{M}_{T}, \mathcal{N}_{T} & \text { body-axis moments due to engine } \\
& \text { thrust; } \\
F_{w x}, F_{w y}, F_{w z} & \text { wind-axis total forces; } \\
D, S, L & \text { drag, side, and lift forces in wind } \\
& \text { axis; } \\
T_{w x}, T_{w y}, T_{w z} & \text { wind-axis thrust. }
\end{array}
$$

The transformation matrix from body axes to wind axes is defined as

$$
L_{W B}=\left[\begin{array}{ccc}
\cos \alpha \cos \beta & \sin \beta & \sin \alpha \cos \beta \\
-\cos \alpha \sin \beta & \cos \beta & -\sin \alpha \sin \beta \\
-\sin \alpha & 0 & \cos \alpha
\end{array}\right] .
$$

The Mach number $M$ is defined as the quotient of airspeed $V$ and local speed of sound $a$

$$
M=\frac{V}{a} .
$$

\section{B. Aerodynamics}

Body-axis aerodynamic forces and moments, $\left(F_{x A}, F_{y A}, F_{z A}\right) \quad$ and $\left(\mathcal{L}_{A}, \mathcal{M}_{A}, \mathcal{N}_{A}\right)$, are represented in terms of the nondimensional aerodynamic coefficients $\left(C_{X}, C_{Y}, C_{Z}\right)$ and $\left(C_{l}, C_{m}, C_{n}\right)$ as follows:

$$
\left\{\begin{array} { l } 
{ F _ { x A } = \frac { 1 } { 2 } \rho V ^ { 2 } S C _ { X } } \\
{ F _ { y A } = \frac { 1 } { 2 } \rho V ^ { 2 } S C _ { Y } } \\
{ F _ { z A } = \frac { 1 } { 2 } \rho V ^ { 2 } S C _ { Z } }
\end{array} \quad \left\{\begin{array}{l}
\mathcal{L}_{A}=\frac{1}{2} \rho V^{2} S b C_{l} \\
\mathcal{M}_{A}=\frac{1}{2} \rho V^{2} S \bar{c} C_{m} \\
\mathcal{N}_{A}=\frac{1}{2} \rho V^{2} S b C_{n}
\end{array}\right.\right.
$$

where $\rho$ denotes the air density, $S$ denotes the aircraft's wing planform area, $b$ denotes the span, and $\bar{c}$ denotes the mean aerodynamic chord.

For the HIRM, the aerodynamic force and moment coefficients are highly nonlinear functions of angle of attack $\alpha$, sideslip angle $\beta$, airspeed $V$, angular rates $p, q, r$, and control deflections (symmetrical and differential taileron deflections $\delta_{T S}$ and $\delta_{T D}$, symmetrical and differential canard deflections $\delta_{C S}$ and $\delta_{C D}$, rudder deflection $\delta_{R}$, and engine throttle $\left.\delta_{T H}\right)$. Each component of the aerodynamic force and moment coefficients is represented by a lookup table. Details on the high-fidelity model can be found in [1].

\section{Formulation of Stochastic Robustness Metrics AND COST FUNCTION}

The stochastic robustness metric characterizes the probability that the closed-loop system will have unacceptable stability 
TABLE I

MANEUVERS AT A SET OF Flight CONDITIONS

\begin{tabular}{|c|c|c|}
\hline & Maneuver & Flight condition \\
\hline 1 & Step inputs to pitch rate demand $+5^{\circ} / \mathrm{s}$ at $\mathrm{t}=2 \mathrm{~s},-5^{\circ} / \mathrm{s}$ at $\mathrm{t}=6 \mathrm{~s}$ & $\begin{array}{l}\mathrm{M}=0.2, \mathrm{~h}=1,000 \mathrm{ft} \\
\mathrm{M}=0.3, \mathrm{~h}=5,000 \mathrm{ft} \\
\mathrm{M}=0.5, \mathrm{~h}=15,000 \mathrm{ft}\end{array}$ \\
\hline$\overline{2}$ & Step inputs to roll rate demand $+70^{\circ} / \mathrm{s}$ at $\mathrm{t}=2 \mathrm{~s},-70^{\circ} / \mathrm{s}$ at $\mathrm{t}=4 \mathrm{~s}$ & $\begin{array}{l}\mathrm{M}=0.3, \mathrm{~h}=5,000 \mathrm{ft} \\
\mathrm{M}=0.5, \mathrm{~h}=15,000 \mathrm{f}\end{array}$ \\
\hline 3 & $\begin{array}{l}\text { Step inputs to sideslip angle demand }+10^{\circ} \text { at } \mathrm{t}=2 \mathrm{~s} \text {, } \\
-10^{\circ} \text { at } \mathrm{t}=6 \mathrm{~s}\end{array}$ & $\begin{array}{l}\mathrm{M}=0.2, \mathrm{~h}=1,000 \mathrm{ft} \\
\mathrm{M}=0.3, \mathrm{~h}=5,000 \mathrm{ft} \\
\mathrm{M}=0.5, \mathrm{~h}=15,000 \mathrm{f}\end{array}$ \\
\hline 4 & Step inputs to air speed demand $+51.48 \mathrm{~m} / \mathrm{s}(100 \mathrm{kn})$ at $\mathrm{t}=2 \mathrm{~s}$ & $\mathrm{M}=0.3, \mathrm{~h}=15,000 \mathrm{ft}$ \\
\hline
\end{tabular}

or performance when subject to parametric uncertainties. The probability, $P$, is defined as

$$
P(\boldsymbol{d})=\int_{\boldsymbol{Q}} I[H(\boldsymbol{q}), C(\boldsymbol{d})] \operatorname{pr}(\boldsymbol{q}) d \boldsymbol{q}
$$

where $H$ is the plant, $\boldsymbol{q}$ is a vector of varying plant parameters in space $\boldsymbol{Q}$ with distribution $\operatorname{pr}(\boldsymbol{q}), C$ is an application-specific controller, and $\boldsymbol{d}$ is the design parameter vector for the controller. For each stability or performance criterion, $I[\cdot]$ is a binary indicator function that equals one if $H(\boldsymbol{q})$ and $C(\boldsymbol{d})$ form an unacceptable system and is zero otherwise. In this paper, the probability in (17) is estimated by Monte Carlo simulations with $\operatorname{pr}(\boldsymbol{q})$ shaping the random samplings of values for $\boldsymbol{q}$. The Monte Carlo estimate of the probability based on $N$ samples is

$$
\widehat{P}(\boldsymbol{d})=\frac{1}{N} \sum_{k=1}^{N} I\left[H\left(\boldsymbol{q}_{k}\right), C(\boldsymbol{d})\right] .
$$

The calculation of confidence intervals of Monte Carlo estimates was explored by [10] and [17].

The objective of the HIRM design challenge is to design a control augmentation system that tracks pilot commands with responses that are in keeping with the handling qualities, across the specified flight envelope and in the presence of uncertain aerodynamic parameters. In this paper, stochastic robustness analysis and control methodologies are applied to designing flight control systems. In the following sections, we present the aircraft command variables, flight envelope, and modeling errors that are specified by the GARTEUR competition [1]. Then, we formulate the stochastic robustness metrics and cost function in keeping with the design specifications of GARTEUR/HIRM.

\section{A. Pilot Commands}

The pilot commands should control the responses as follows: lateral stick deflection commands velocity-vector roll rate $p_{w c}$, which is a roll performed at constant angle of attack and zero sideslip; longitudinal stick deflection commands pitch rate $q_{c}$; rudder pedal deflection commands sideslip angle $\beta_{c}$; throttle lever deflection commands velocity-vector air speed $V_{c}$, which represents a step command from its trim value $V_{\text {trim }}$.

\section{B. Design Envelope}

The flight envelope that is specified by the GARTEUR/HIRM competition and used in comparison has Mach number within $(0.15,0.5)$, angle of attack $\left(-10^{\circ}, 30^{\circ}\right)$, sideslip angle $\left(-10^{\circ}, 10^{\circ}\right)$, and altitude $(100 \mathrm{ft}, 20000 \mathrm{ft})$.

\section{Modeling Errors}

The control system should be robust to the errors in the aerodynamic moment derivatives and to the biases in the total moment coefficients. The variation of $C_{m_{w}}$ is within (-0.001, $0.001)$, variation of $C_{l_{v}}$ is within $(-0.01,0.01)$, and the variation of $C_{n_{v}}$ is within $(0.002,0.002)$. The variations of $C_{m_{q}}, C_{l_{p}}$, $C_{n_{r}}, C_{l_{r}}, C_{n_{p}}, C_{m_{T S}}, C_{m_{C S}}, C_{l_{T D}}, C_{l_{C D}}, C_{l_{\mathrm{RUDDER}}}, C_{n_{T D}}$, $C_{n_{C D}}$, and $C_{n_{\mathrm{RUDDER}}}$ are within $(-10 \%, 10 \%)$ of the derivatives' trim values. Though these uncertainties are proposed for linear analysis in [1], we include these aerodynamic-moment-derivative uncertainties in the assessment of nonlinear time responses. We assume that the uncertainties take uniform distributions in the designated ranges.

\section{Formulation of the Robustness Metrics}

A set of maneuvers of the HIRM aircraft are specified by the GARTEUR competition to evaluate nonlinear time responses of step inputs listed in Table I. In Table II, we formulate robustness metrics in keeping with performance requirements in the assessments of maneuvers listed in Table I. All the robustness metrics are evaluated by Monte Carlo simulations with random number generators providing possible values of the uncertain aerodynamic parameters. It is assumed that the uncertain parameters take uniform distributions in the designated ranges.

In Table II, the first indicator function, $I_{i}$, measures system stability. The system stability is evaluated in terms of the simulation of nonlinear time responses. If all of the step command responses listed in Table I do not have finite escape time, we specify $I_{i}=0$; otherwise, $I_{i}=1$. Indicator functions $2-9$ 
TABLE II

FORMULATION OF ROBUSTNESS METRICS

\begin{tabular}{|c|c|c|c|}
\hline Metric & $\begin{array}{l}\text { Weight } \\
\text { in J }\end{array}$ & $\begin{array}{l}\text { Indicator } \\
\text { Function }\end{array}$ & $\begin{array}{l}\text { Design } \\
\text { Requirement }\end{array}$ \\
\hline 1 & 10 & $I_{i}$ & Stability at all flight conditions \\
\hline \multicolumn{4}{|c|}{ Pitch rate command responses } \\
\hline 2,3 & 1.0 & $\begin{array}{l}I_{3 q_{-} q T S} \\
I_{5 q_{-} q T s}\end{array}$ & $\begin{array}{l}10 \% \text { settling time less than } 2 \mathrm{~s} \text { for pitch rate command response at } \mathrm{M}=0.3 \\
\text { and } 0.5\end{array}$ \\
\hline $4,5,6$ & 0.1 & $\begin{array}{l}I_{2 q_{-} a \max } I_{3 q_{-} a \max } \\
I_{5 q_{-} a \max }\end{array}$ & $-10^{\circ}<\alpha<30^{\circ}$ for pitch rate demand response at $\mathrm{M}=0.2,0.3$, and 0.5 \\
\hline $7,8,9$ & 0.1 & $\begin{array}{l}I_{2 q_{-} z \max } \\
I_{3 q_{-} z \max } \\
I_{5 q_{-} z \max }\end{array}$ & $-3 g<a_{n z}<7 g$ for pitch rate demand response at $\mathrm{M}=0.2,0.3$, and 0.5 \\
\hline \multicolumn{4}{|c|}{ Velocity command response } \\
\hline 10 & 1.0 & $I_{3 V_{-} V T s}$ & $10 \%$ settling time less than $15 \mathrm{~s}$ for velocity response at $\mathrm{M}=0.3$ \\
\hline 11 & 0.1 & $I_{3 V_{-} q t}$ & Pitch rate transient less than $10^{\circ} / \mathrm{s}$ at $\mathrm{M}=0.3$ \\
\hline \multicolumn{4}{|c|}{ Sideslip command responses } \\
\hline 12,1314 & 1.0 & $\begin{array}{c}I_{2 b}, I_{3 b}, \\
I_{5 b}\end{array}$ & $\begin{array}{l}\text { Sideslip command response lies within specified boundaries at } \mathrm{M}=0.2,0.3 \text {, } \\
\text { and } 0.5\end{array}$ \\
\hline \multicolumn{4}{|c|}{ Roll rate command responses } \\
\hline 15,16 & 1.0 & $\begin{array}{l}I_{3 p_{-} p T s} \\
I_{5 p_{-} p T_{s}}\end{array}$ & $\begin{array}{l}10 \% \text { settling time less than } 2 \mathrm{~s} \text { for roll rate command response at } \mathrm{M}=0.3 \text { and } \\
0.5\end{array}$ \\
\hline 17,18 & 0.1 & $\begin{array}{l}I_{3 p_{-} q t} \\
I_{5 p_{-} q t}\end{array}$ & $\begin{array}{l}\text { Pitch rate transient less than } 5^{\circ} / \mathrm{s} \text { for roll rate command response at } \mathrm{M}= \\
0.3 \text { and } 0.5\end{array}$ \\
\hline
\end{tabular}

characterize the nonlinear time responses to step pitch-rate commands at different flight conditions. The angles of attack during pitch-rate commands should be within the specified limits with maximum overshoot less than $5^{\circ}$. The normal acceleration should be within the specified limits with maximum overshoot less than $0.5 \mathrm{~g}$. The settling time requirement is not specified for the pitch-rate response at $M=0.2$ because the necessity of an angle-of-attack limiter could cause transients of the pitch rate. Indicator functions 10-11 characterize the step velocity command response at $\mathrm{M}=0.3$. Indicator functions 12-14 are for sideslip-angle command responses. The step response to sideslip command should lie within some specified boundaries [1]. Indicator functions 15-18 illustrate the requirements for roll-rate command responses.

The stochastic robustness cost function chosen to guide the design is a weighted quadratic sum of the eighteen probabilities of design metric violations

$$
J=\sum_{j=1}^{18} w_{j} P_{j}^{2}
$$

The weight for each probability is given in Table II. One of the advantages of the cost function (19) is that it explicitly takes into account each design specification, and the final design will provide a direct answer on how likely it is that each design requirement will not be satisfied.

\section{CONTROller Structure}

The design of the controller structure is based on nonlinear dynamic inversion [2]-[9]. It is possible to separate system dynamics into two time scales if one subset of the state components (referred to as "fast dynamics") is known to evolve in a much faster time scale than the other subset (referred to as "slow dynamics"). The inversion performed here is based on the assumption that the dynamics of angular rates are faster than those of angles of attack and sideslip. The design of controller structure is separated into two steps relating to the slow and fast dynamics.

For the slow dynamics, commanded angular rates are derived through either direct pilot inputs or the inversion of the force equations. The engine throttle position is derived through the inversion of the velocity dynamics. The values of yaw rate and engine throttle are obtained in terms of design parameters that characterize desired dynamics of sideslip angle and velocity. For the fast dynamics, control surface deflections are derived explicitly through the inversion of a first-order differentiation of angular velocities. They are defined in terms of design parameters that characterize desired dynamics of angular rates. The 


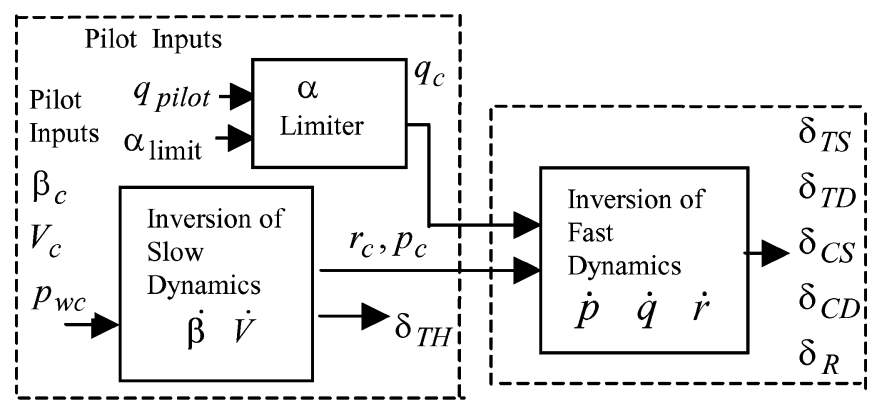

Controller for slow dynamics Controller for fast dynamics

Fig. 1. Controller structure designed using two-time-scale nonlinear dynamic inversion.

procedure of this two-time-scale nonlinear dynamic inversion is illustrated in Fig. 1.

\section{A. Slow Dynamics}

Design of the controller for slow dynamics shown in Fig. 1 deals with force equations and the kinematic equation for velocity-vector roll rate. The purpose of this inversion is to derive commanded angular rates $\left(p_{c}, r_{c}\right)$ for the fast dynamics from the pilot commands $\left(p_{w c}, \beta_{c}\right)$, and to derive engine throttle position $\delta_{T H}$ from the pilot command velocity $V_{c}$.

First, we rewrite the equations for $\dot{\alpha}, \dot{\beta}, \dot{V}$, and $p_{w}$ in appropriate forms. The wind-axis thrust induced by the two engines is derived from the body-axis thrust

$$
\begin{aligned}
{\left[\begin{array}{c}
T_{x w} \\
T_{y w} \\
T_{z w}
\end{array}\right] } & =L_{W B}\left[\begin{array}{l}
T_{x} \\
T_{y} \\
T_{z}
\end{array}\right] \\
& =L_{W B}\left[\begin{array}{c}
2 F_{E} \\
0 \\
0
\end{array}\right] \\
& =\left[\begin{array}{c}
2 F_{E} \cos \alpha \cos \beta \\
-2 F_{E} \cos \alpha \sin \beta \\
-2 F_{E} \sin \alpha
\end{array}\right] .
\end{aligned}
$$

By (20), (13) becomes

$$
\left[\begin{array}{c}
F_{w x} \\
F_{w y} \\
F_{w z}
\end{array}\right]=\left[\begin{array}{c}
-D+2 F_{E} \cos \alpha \cos \beta \\
-S-2 F_{E} \cos \alpha \sin \beta \\
-L-2 F_{E} \sin \alpha
\end{array}\right]
$$

We define wind-axis load factors as

$$
\begin{aligned}
& n_{w x}=\frac{F_{w x}}{m g}=\frac{-D+2 F_{E} \cos \alpha \cos \beta}{m g} \\
& n_{w y} \equiv \frac{F_{w y}}{m g}=\frac{-S-2 F_{E} \cos \alpha \sin \beta}{m g} \\
& n_{w z} \equiv \frac{F_{w z}}{m g}=\frac{-L-2 F_{E} \sin \alpha}{m g} .
\end{aligned}
$$

Equations (9) and (10) are rewritten in terms of wind-axis load factors as

$$
\begin{aligned}
& q_{w}=-\frac{g}{V}\left(\cos \gamma \cos \varphi+n_{w z}\right) \\
& r_{w}=\frac{g}{V}\left(\cos \gamma \cos \varphi+n_{w y}\right) .
\end{aligned}
$$

By setting $\dot{\alpha}$ and $\beta$ to zero in (11), we have

$$
p_{w c}=(p \cos \alpha+r \sin \alpha) .
$$

With (26) and (27), (3) becomes

$$
\dot{\beta}=-\frac{r}{\cos \alpha}+p_{w c} \tan \alpha+\frac{g}{V}\left(n_{w y}+\cos \gamma \cos \varphi\right) \cos \alpha .
$$

By (21), (1) becomes

$$
\dot{V}=\frac{\left(2 F_{E} \cos \alpha \cos \beta-D\right)}{m}-g \sin \gamma
$$

Next, we formulate the state and control inputs for the slow dynamics. Integral compensation is used to minimize steadystate error of the command response. Therefore, we define new state variables

$$
\begin{aligned}
& V_{I}=\int_{0}^{t}\left[V(\tau)-\left(V_{\text {trim }}+V_{c}\right)\right] d \tau \\
& \beta_{I}=\int_{0}^{t}\left(\beta(\tau)-\beta_{c}\right) d \tau .
\end{aligned}
$$

The corresponding augmented state vector for slow dynamics is defined as

$$
\boldsymbol{x}_{s}=\left[\begin{array}{llll}
V_{I} & V & \beta_{I} & \beta
\end{array}\right]^{T} .
$$

The dynamic model for $\boldsymbol{x}_{s}$ is

$$
\left[\begin{array}{c}
\dot{V}_{I} \\
\dot{V} \\
\dot{\beta}_{I} \\
\dot{\beta}
\end{array}\right]=\left[\begin{array}{c}
V-\left(V_{\text {trim }}+V_{c}\right) \\
-2 \xi_{V} \omega_{V}\left[V-\left(V_{\text {trim }}+V_{c}\right)\right]-\omega_{V}^{2} V_{I} \\
\beta-\beta_{c} \\
-2 \xi_{\beta} \omega_{\beta}\left(\beta-\beta_{c}\right)-\omega_{\beta}^{2} \beta_{I}
\end{array}\right]
$$

where $\xi_{V}, \omega_{V}, \xi_{\beta}$, and $\omega_{\beta}$ are design parameters. $\xi_{V}$ and $\omega_{V}$ denote the desired damping ratio and frequency for velocity dynamics, while $\xi_{\beta}$ and $\omega_{\beta}$ denote the desired damping ratio and frequency for the dynamics of sideslip angle.

The control vector for slow dynamics consists of the thrust of each engine $F_{E}$ and the commanded yaw rate $r_{c}$ for the fast dynamics. Utilizing (28), (29), and (33), we derive the control vector $\boldsymbol{u}_{s}=\left[\begin{array}{ll}F_{E} & r_{c}\end{array}\right]^{T}$

$$
\begin{aligned}
F_{E}= & \frac{m}{2 \cos \alpha \cos \beta} \\
& \cdot\left[\frac{D}{m}+g \sin \gamma-2 \xi_{V} \omega_{V}\left[V-\left(V_{\operatorname{trim}}+V_{c}\right)\right]-\omega_{V}^{2} V_{I}\right] \\
r_{c}= & p_{w c} \cos \beta \sin \alpha+\frac{g}{V}\left(n_{w y}+\cos \gamma \sin \varphi\right) \cos \alpha \\
& +\left[2 \xi_{\beta} \omega_{\beta}\left(\beta-\beta_{c}\right)+\omega_{\beta}^{2} \beta_{I}\right] \cos \alpha .
\end{aligned}
$$

By (27) and (35), we derive the commanded roll rate $p_{c}$ for the fast dynamics as

$$
\begin{aligned}
& p_{c}=p_{w c} \cos \beta \cos \alpha-\frac{g}{V}\left(n_{w y}+\cos \gamma \sin \varphi\right) \sin \alpha \\
&-\left[+2 \xi_{\beta} \omega_{\beta}\left(\beta-\beta_{c}\right)+\omega_{\beta}^{2} \beta_{I}\right] \sin \alpha .
\end{aligned}
$$

In terms of the engine model in [1], the throttle position is

$$
\delta_{T H}= \begin{cases}\frac{F_{E} \cdot \frac{\rho_{0}}{\rho}-F_{\mathrm{IDLE}}}{F_{\mathrm{MD}}-F_{\mathrm{IDLE}}}, & F_{E} \cdot \frac{\rho_{0}}{\rho}<F_{\mathrm{MD}} \\ 1+\frac{F_{E} \cdot \frac{\rho_{0}}{\rho}-F_{\mathrm{MD}}}{F_{\mathrm{MR}}-F_{\mathrm{MD}}}, & F_{\mathrm{MD}} \leq F_{E} \cdot \frac{\rho_{0}}{\rho} \leq F_{\mathrm{MR}}\end{cases}
$$


with $F_{E}$ given by (34). $F_{\mathrm{IDLE}}, F_{\mathrm{MD}}$, and $F_{\mathrm{MR}}$ denote the idle thrust, maximum dry thrust, and maximum reheat thrust for the engine.

The computation of $r_{c}, p_{c}$ and $F_{E}$ is conducted as follows. Through the transformation from body axes to wind axes $L_{W B}$, the wind-axis load factor $n_{w y}$ in (35) and (36) is calculated from the body-axis accelerations $a_{n x}, a_{n y}$, and $a_{n z}$, which are measured variables. Also through $L_{W B}$, drag $D$ in (34) is calculated from body-axis aerodynamic forces $F_{x A}, F_{y A}$, and $F_{z A}$, which are computed in terms of the aerodynamic force coefficients $C_{X}, C_{Y}$, and $C_{Z}$ by (16). The calculation of $C_{X}, C_{Y}$, and $C_{Z}$ depends on the values of control surface deflections, which are unknown and are computed in the phase of fast dynamics. In this paper, the values of control surface deflections of the previous time iteration are used in computing aerodynamic force coefficients $C_{X}, C_{Y}$, and $C_{Z}$.

An angle-of-attack limiter is important because the commanded pitch rate $q_{c}$, which is an input for the fast dynamics, should be chosen as the minimum of the pilot-commanded pitch rate $q_{\text {pilot }}$ and the pitch rate $q_{\text {limit }}$ that would induce the maximum allowable angle of attack $\alpha_{\text {limit }}$

$$
q_{c}=\min \left(q_{\mathrm{pilot}}, q_{\text {limit }}\right) \text {. }
$$

In terms of (2) and (25), $q_{\text {limit }}$ is derived as

$$
\begin{aligned}
q_{\text {limit }}=(p \cos \alpha+r & \sin \alpha) \tan \beta \\
& -\frac{g}{V} \frac{\left(n_{w z}+\cos \gamma \cos \varphi\right)}{\cos \beta}+\dot{\alpha}_{L I M}
\end{aligned}
$$

where the maximum allowable angle-of-attack rate, $\dot{\alpha}_{L I M}$, is calculated from

$$
\dot{\alpha}_{L I M}=-\omega_{\alpha}\left(\alpha-\alpha_{\text {limit }}\right)
$$

where $\omega_{\alpha}$ denotes the bandwidth of the angle-of-attack control loop, and it is a design parameter. $\alpha$ is the current angle of attack. The limit of angle of attack $\alpha_{\text {limit }}$ equals $30^{\circ}$.

\section{B. Fast Dynamics}

Design of the controller corresponding to the fast dynamics in Fig. 1 consists of the inversion of the moment equations. The purpose of this inversion is to derive a vector of control surface deflections for a given set of commanded angular rates $p_{c}, q_{c}$ and $r_{c}$.

Integral compensation minimizes the steady-state error of the pitch rate command response, thus, we define a new state variable

$$
q_{I}=\int_{0}^{t}\left(q(\tau)-q_{c}\right) d \tau
$$

The state vector for the fast dynamics is

$$
\boldsymbol{x}_{f}=\left[\begin{array}{llll}
p & r & q_{I} & q
\end{array}\right]^{T} .
$$

The dynamic model for angular rates is

$$
\dot{p}=-\omega_{p}\left(p-p_{c}\right)
$$

$$
\begin{aligned}
& \dot{r}=-\omega_{r}\left(r-r_{c}\right) \\
& \dot{q}=-2 \xi_{q} \omega_{q}\left(q-q_{c}\right)-\omega_{q}^{2} q_{I}
\end{aligned}
$$

where $\xi_{q}, \omega_{q}, \omega_{p}$, and $\omega_{r}$ are design parameters. $\xi_{q}$ and $\omega_{q}$ denote the desired damping ratio and frequency for the dynamics of pitch rate while $\omega_{p}$ and $\omega_{r}$ denote the desired bandwidths for $p$ and $r$.

The vector of control inputs for the fast dynamics consists of control surface deflections of the taileron, canard, and rudder

$$
\boldsymbol{u}_{f}=\left[\begin{array}{lllll}
\delta_{T S} & \delta_{T D} & \delta_{C S} & \delta_{C D} & \delta_{R}
\end{array}\right]^{T} .
$$

From (7), (8), (12), and (43)-(45), we have

$$
\begin{aligned}
& {\left[\begin{array}{c}
\mathcal{L}_{A} \\
\mathcal{N}_{A} \\
\mathcal{M}_{A}
\end{array}\right]=-\left[\begin{array}{c}
\mathcal{L}_{T} \\
\mathcal{N}_{T} \\
\mathcal{M}_{T}
\end{array}\right]+\left[\begin{array}{c}
-I_{x z} p q+\left(I_{z z}-I_{y y}\right) q r \\
I_{x z} q r+\left(I_{y y}-I_{x x}\right) p q \\
\left(I_{x x}-I_{z z}\right) r p+I_{x z}\left(p^{2}-r^{2}\right)
\end{array}\right]} \\
& +\left[\begin{array}{ccc}
I_{x x} & -I_{x z} & 0 \\
-I_{x z} & I_{z z} & 0 \\
0 & 0 & I_{y y}
\end{array}\right]\left[\begin{array}{c}
-\omega_{p}\left(p-p_{c}\right) \\
-\omega_{r}\left(r-r_{c}\right) \\
-2 \xi_{q} \omega_{q}\left(q-q_{c}\right)-\omega_{q}^{2} q_{I}
\end{array}\right] .
\end{aligned}
$$

Note that the aerodynamic moments $\mathcal{L}_{A}, \mathcal{N}_{A}$, and $\mathcal{M}_{A}$ are nonlinear functions of the control surface deflections $\boldsymbol{u}_{f}$; the inverse mappings of these nonlinear functions have to be calculated in order to derive the control surface deflections $\boldsymbol{u}_{f}$. For simplicity of calculation, we approximate the aerodynamic moments by their first-order expansions with respect to control surface deflections around the values of control surface deflections at the previous time iteration

$$
\left[\begin{array}{c}
\mathcal{L}_{A} \\
\mathcal{N}_{A} \\
\mathcal{M}_{A}
\end{array}\right] \cong \frac{1}{2} \rho V^{2} S \cdot \mathcal{D} \cdot\left(\boldsymbol{u}_{f}-\boldsymbol{u}_{f}^{*}\right)+\frac{1}{2} \rho V^{2} S \cdot \mathcal{E} .
$$

Matrices $\mathcal{D}$ and $\mathcal{E}$, which are functions of the control surface deflections at the previous time iteration $\boldsymbol{u}_{f}^{*}$, are given in [22].

Note that in (48), we have more unknown variables ( $\boldsymbol{u}_{f}$ consists of five control surface deflections) than equations (three equations), hence, the solution of $\boldsymbol{u}_{f}$ is not unique. We derive the control $\boldsymbol{u}_{f}$ in terms of $\mathcal{D}^{\#}$, which is the pseudoinverse of matrix $\mathcal{D}$

$$
\boldsymbol{u}_{f}=\boldsymbol{u}_{f}^{*}+\mathcal{D}^{\#} \cdot\left\{\frac{1}{\frac{1}{2} \rho V^{2} S} \cdot\left[\begin{array}{c}
\mathcal{L}_{A} \\
\mathcal{N}_{A} \\
\mathcal{M}_{A}
\end{array}\right]-\mathcal{E}\right\}
$$

where $\left[\begin{array}{lll}\mathcal{L}_{A} & \mathcal{N}_{A} & \mathcal{M}_{A}\end{array}\right]^{T}$ is given by (47). The (right) pseudoinverse operation used here corresponds to a minimization of the normalized control surface deflections.

We concatenate the control design parameters in (33) and (43)-(45) into a single design vector as

$$
\boldsymbol{d}=\left[\begin{array}{lllllllll}
\xi_{V} & \omega_{V} & \xi_{\beta} & \omega_{\beta} & \omega_{\alpha} & \xi_{q} & \omega_{q} & \omega_{p} & \omega_{r}
\end{array}\right]^{T} .
$$

\section{Control Design Results and Simulations of Nominal CONTROL RESPONSES}

There are two fundamental difficulties in optimization of the cost function in (19): the evaluation of the probability 

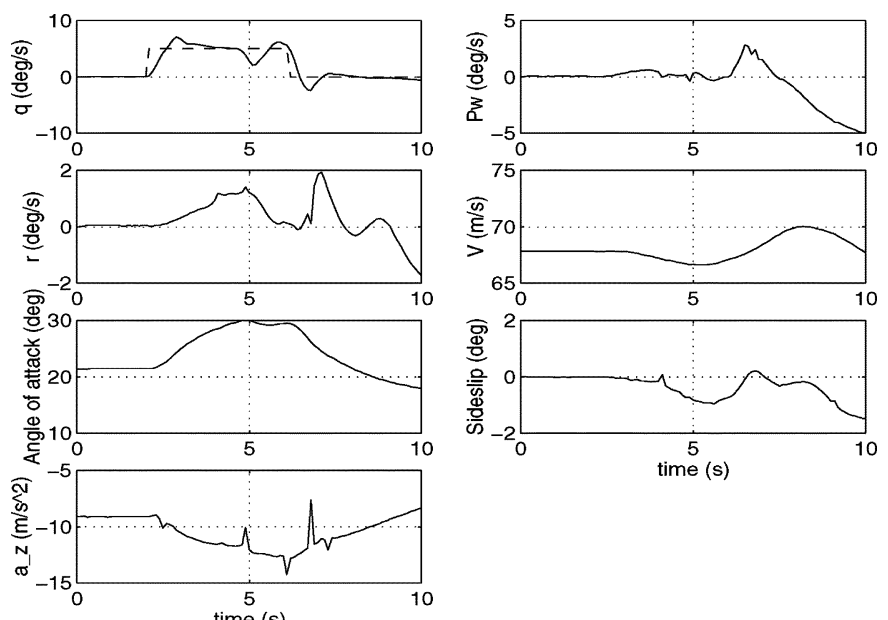

Fig. 2. Pitch rate command response at $\mathrm{M}=0.2$.

by Monte Carlo simulation is not deterministic, and the cost function is nonconvex, with the possibility of multiple minima and large plateau areas. Reference [15] has provided a comprehensive analysis of the shape and characteristics of a general stochastic robustness cost function that is a weighted quadratic sum of probabilities. Therefore, conventional (stochastic) gradient-based algorithms are not effective in minimizing such a nonconvex cost function as (19). In this paper, we use a genetic algorithm [23] to search the control design parameters. Genetic algorithms implement a direct search that does not use gradient or Hessian information; hence, it does not require that the objective function be continuous and differentiable. Through probabilistic operations such as crossover and mutation, genetic algorithms are less likely to become trapped in a local minimum and more likely to identify global minima. As addressed in [23], genetic algorithms have probabilistic convergence. The optimal gap of the solution found by genetic algorithms from the global optimality could be analyzed using statistical estimation theory, as illustrated in [12]. In the GA search, each function evaluation of (19) is completed by Monte Carlo simulations. The number of Monte Carlo simulations used in estimating the probabilities during GA search and the overall computation cost for this paper is addressed in Section IX.

The design parameter vector in (50) for our robust HIRM controller found by using a genetic algorithm is as follows:

$\boldsymbol{d}=\{0.419,1.046,2.872,0.489$

$$
4.983,1.448,3.063,4.023,2.663\} \text {. }
$$

The performance of the nominal closed-loop system is illustrated by a set of maneuvers in Figs. 2-5; the time responses for other maneuvers can be found in [22]. The figures show histories of the command variables and state variables of interest. The command values of pitch-rate, velocity-vector-roll-rate, airspeed, and sideslip angle are plotted using dashed lines. The response to command is good in all cases.

For the $5 \%$ pitch rate commanded response at $\mathrm{M}=0.2$, Fig. 2 shows angle of attack being limited to the maximum value, $30^{\circ}$. The pitch-rate transient that occurs at $t=5 \mathrm{~s}$ is due to this limiting. With the increase of the pitch attitude, the gravitational force component from the mass of the aircraft induces
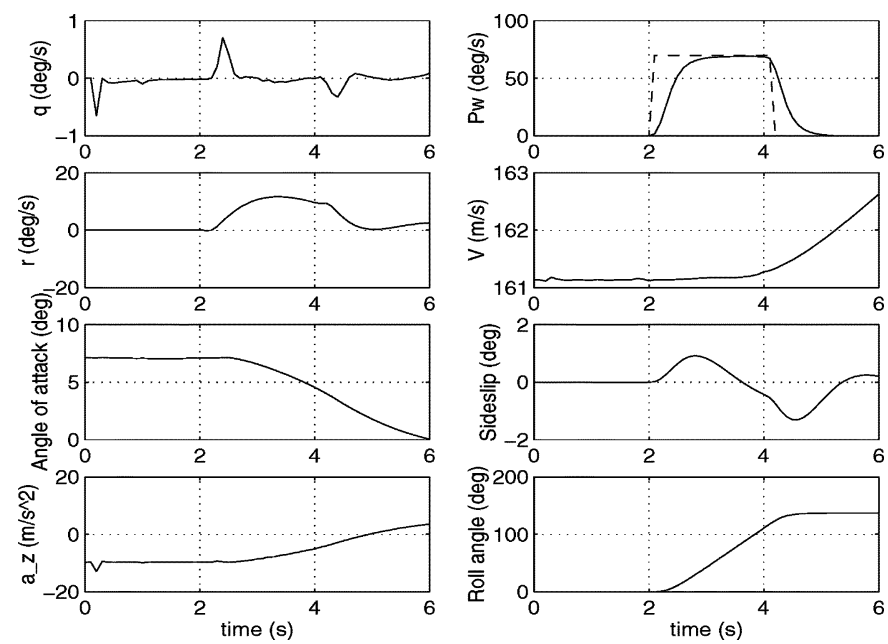

Fig. 3. Roll rate command response at $\mathrm{M}=0.5$.
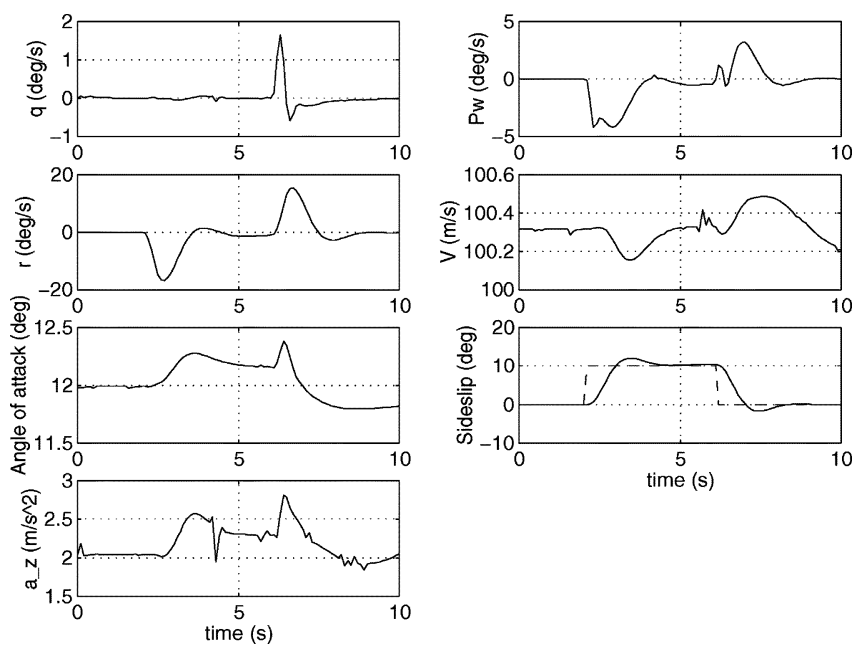

Fig. 4. Sideslip angle command response at $\mathrm{M}=0.3$.

an additional force in the wind $\mathrm{x}$-axis that results in the variation of the airspeed. The thrust is increased to compensate for the change in attitude.

For the $70 \%$ soll rate commanded response at $\mathrm{M}=0.5$, Fig. 3 shows good performance. The roll rate follows the command input quite well, with $10 \%$ settling time less than $2 \mathrm{~s}$. The coupling to sideslip angle is less than $1.5^{\circ}$, and the coupling to pitch rate is less than $1 \%$.

Fig. 4 illustrates the responses due to a $10 \%$ step command on sideslip angle at $\mathrm{M}=0.3$. The time history of the sideslip angle is well within the specified boundaries. It follows the command input with $10 \%$ settling time of less than $2 \mathrm{~s}$. The couplings into roll and pitch rate are low.

Fig. 5 shows a $51.48 \mathrm{~m} / \mathrm{s}(100-\mathrm{kn})$ step on velocity commanded response at $\mathrm{M}=0.3$. The $10 \%$ settling time is less than $15 \mathrm{~s}$, and the overshoot is within $3 \%$. The pitch rate transient is low and returns to zero quickly. The engine is fully used for the rapid speed command change. The maximum throttle position is attained. The noise in the time history of normal acceleration $a_{z}$ is due to the relatively high bandwidth of the velocity. The control system shows good performance for the entire flight envelope including extreme flight conditions such as $30^{\circ}$ angle of 

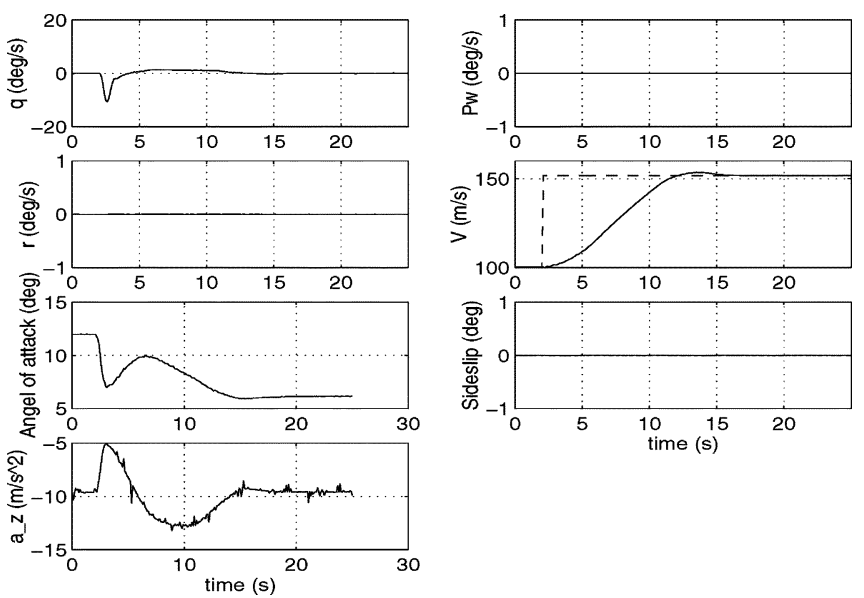

Fig. 5. Velocity command response at $M=0.3$.

attack. It is demonstrated that the controller has strong ability to account for significant nonlinearities.

\section{Comparison of Present Design With Controllers DEVELOPED FOR GARTEUR COMPETITION}

A set of control designs has been presented for the HIRM control challenge in the GARTEUR competition [24]. They include controllers based on linear-quadratic (LQ) methods [25], $H_{\infty}$ loop-shaping approaches [26], $\mu$ synthesis [27], [28], nonlinear dynamic inversion combined with linear-quadratic regulator (NDI/LQ) [29], and robust inverse dynamics estimation approaches (RIDE) [30]. The first three design approaches are linear techniques. Gain scheduling of linear feedback gains was utilized to cover the whole operating envelope of the aircraft. Reference [29] used a two-level controller structure consisting of a nonlinear-dynamic-inversion feedforward controller and a linear-quadratic feedback controller. In [29], the simulations for the nonlinear time responses were performed with the nonlinear-dynamic-inversion feedforward controller alone, without the linear-quadratic correction. Reference[30] combined dynamic inversion with proportional and integral feedback loops. Robustness issues were not directly taken into account in [30].

It is difficult to compare the present controller in this paper against the designs presented in the GARTEUR competition because they were not intended to minimize the probabilities of metric violations subject to expected parameter variations, as is the present design. In the evaluation software provided by GARTEUR, a single set of values of uncertain parameters is used to test a control system's robustness (deterministic characterization of uncertainties). Furthermore, very limited simulation results were presented for each design. Nevertheless, we provide a comparison of the present controller with the earlier designs based on the available information.

\section{A. Performance in Nominal Control Responses}

For each design in the GARTEUR competition, maneuver simulations are offered only at some of the flight conditions. There are no results shown for the commanded time responses in the presence of parametric uncertainties. A comparison of the performance of nominal time responses for a set of maneuvers between the present controller and previous designs is given in Table III.

In Table III, "Ts" denotes a 10\% settling time for a command response. "Tw" represents the overshoot wash-out time for the angle of attack above its limiting value. A two-second wash-out time is required. We use "_" to denote unavailable results. Inadequate performances of each control design are highlighted.

The linear-quadratic design has quite good performance except that there is a slight excess of overshoot in the velocity command response, compared to the desired specification of less than $3 \%$. The $H_{\infty}$ loop-shaping controller has excess wash-out time for angle-of-attack overshoot above $30^{\circ}$ in the pitch-rate command response, excess steady-state offsets of the roll-rate command response, and excess overshoot in the velocity command response. The first $\mu$-synthesis design has large steadystate offsets for the pitch-rate command response and excess settling time for the roll-rate command response. The second $\mu$-synthesis design has very good performance, except the settling time is longer than the required two seconds for the pitch rate command response. The NDI/LQ design has large overshoot in the velocity command response; otherwise, it demonstrates excellent nominal performance. The RIDE design has no overshoot in velocity, but there are slight steady-state offsets, and it has relatively long settling time for the sideslipangle command response. Compared to previous designs in the GARTEUR competition, the controller presented in this paper shows less overshoot in the velocity command response, faster response in all the maneuvers, and more accurate tracking of the commands without steady-state offsets.

\section{B. Performance Robustness in Linear Frequency Responses With Parametric Uncertainties}

In the GARTEUR competition, the evaluation software analyzes linear frequency responses of controllers in the presence of parametric uncertainties in moment derivatives. Linear frequency specifications have less value for our nonlinear control law; therefore, we do not include them in the formulation of our cost function. Nevertheless, our controller is evaluated against linear frequency requirements specified in the GARTEUR competition for comparison with the earlier designs. The open-loop Nichols plot of the frequency response between each actuator demand $u$ and the corresponding error signal $e$ should avoid a gain-phase exclusion region. The evaluation is made in the presence of parametric uncertainties as: $C_{m_{w}}=-0.001$, $C_{l_{v}}=-0.01, C_{n_{v}}=-0.002, C_{l_{r}}, C_{n_{p}}=10 \%$, and $C_{m_{q}}$, $C_{l_{p}}, C_{n_{r}}, C_{m_{T S}}, C_{m_{C S}}, C_{l_{T D}}, C_{l_{C D}}, C_{l_{\mathrm{RUDDER}}}, C_{n_{T D}}, C_{n_{C D}}$, $C_{n_{\text {RUDDER }}}=-10 \%$.

Open-loop Nichols plots for the present controller with parametric uncertainties are plotted in Fig. 6 for a flight condition at Mach $0.24,20000 \mathrm{ft}$ altitude, $28.9^{\circ}$ angle of attack, and zero sideslip angle. This flight condition represents an edge of the flight envelope, which is likely to cause stability and actuatorlimiting problems. Fig. 6 shows that the frequency responses for all of the six control loops (differential and symmetrical taileron loops; differential and symmetrical canard loops; rudder loop, and thrust loop) avoid the specified gain-phase exclusion zone. 
TABLE III

COMPARISON OF NOMINAL PERFORMANCE FOR A SET OF CONTROLlers

\begin{tabular}{|c|c|c|c|c|c|c|c|}
\hline & LQ & $H_{\infty}$ & $\mu-1$ & $\mu-2$ & NDI/LQ & RIDE & Present \\
\hline \multicolumn{8}{|c|}{ Pitch rate command responses } \\
\hline $\mathrm{M}=0.2$ & & & & & & & \\
\hline (AOA limiter) & - & $\begin{array}{l}\alpha>30^{\circ} \\
\text { with } 1.5^{\circ} \\
\text { overshoot, } \mathrm{Tw}> \\
2 \mathrm{~s}\end{array}$ & - & - & $\begin{array}{l}\alpha \leq 30^{\circ} \\
\text { without } \\
\text { overshoot }\end{array}$ & - & $\begin{array}{l}\alpha \leq 30^{\circ} \\
\text { without } \\
\text { overshoot }\end{array}$ \\
\hline $\mathrm{M}=0.3$ & $T s<2 s$ & - & $\mathrm{Ts}<2 \mathrm{~s}$ & $\mathrm{Ts}>2 \mathrm{~s}$ & - & - & $\mathrm{Ts}<2 \mathrm{~s}$ \\
\hline $\begin{array}{l}\mathrm{M}=0.4(\mathrm{AOA} \\
\text { limiter })\end{array}$ & - & - & - & - & - & $\begin{array}{l}\alpha \leq 30^{\circ} \\
\text { without } \\
\text { overshoot }\end{array}$ & - \\
\hline $\mathrm{M}=0.5$ & - & - & $q$ offset $=14 \%$ & - & - & - & $\mathrm{Ts}<2 \mathrm{~s}$ \\
\hline \multicolumn{8}{|c|}{ Roll rate command responses } \\
\hline $\mathrm{M}=0.3$ & $\begin{array}{l}\text { Ts }<2 \mathrm{~s},|q|<7 \\
\% \mathrm{~s}|\beta|<4 \\
0\end{array}$ & $\begin{array}{l}p_{w} \text { offsets }= \\
20 \%,|q|<5 \\
\%,|\beta|<1.2 \\
\end{array}$ & $\begin{array}{l}\text { Ts }>2 \mathrm{~s}|q|<8 \\
\% \mathrm{~s}|\beta|<0.7\end{array}$ & & & & $\begin{array}{l}\text { Ts }<2 \mathrm{~s},|q|<4 \\
\% / \mathrm{s},|\beta|<2\end{array}$ \\
\hline $\mathrm{M}=0.4$ & - & - & - & - & $\begin{array}{l}\text { Ts }<2 \mathrm{~s}|q|<2 \\
\% / \mathrm{s}\end{array}$ & $\begin{array}{l}\text { Ts }<2 s|q|<3 \\
\% / s\end{array}$ & - \\
\hline $\mathrm{M}=0.5$ & - & - & - & $\begin{array}{l}\text { Ts }<2 \mathrm{~s}|q|<1 \\
\% / \mathrm{s}\end{array}$ & - & - & $\begin{array}{l}\text { Ts }<2 \mathrm{~s}|q|<1 \\
\% / \mathrm{s}\end{array}$ \\
\hline \multicolumn{8}{|c|}{ Sideslip angle command responses } \\
\hline $\mathrm{M}=0.2$ & - & - & - & - & - & - & Ts $<2 \mathrm{~s}$ \\
\hline $\mathrm{M}=0.3$ & Ts $<2 \mathrm{~s}$ & - & - & - & - & - & Ts $<2 \mathrm{~s}$ \\
\hline $\mathrm{M}=0.4$ & - & - & - & - & $\mathrm{Ts}<2 \mathrm{~s}$ & $\mathrm{Ts}>2 \mathrm{~s}$ & - \\
\hline $\mathrm{M}=0.5$ & - & $\mathrm{Ts}<2 \mathrm{~s}$ & - & - & - & - & $\mathrm{Ts}<2 \mathrm{~s}$ \\
\hline \multicolumn{8}{|c|}{ Velocity command response } \\
\hline $\mathrm{M}=0.3$ & Overshoot $=8 \%$ & Overshoot $=6.7 \%$ & - & - & $\begin{array}{l}\text { Overshoot }= \\
20 \%, \text { steady } \\
\text { offsets }=6 \%\end{array}$ & $\begin{array}{l}\text { Overshoot }=0, \\
\text { steady offsets }= \\
4.5 \%\end{array}$ & Overshoot $<3 \%$ \\
\hline
\end{tabular}

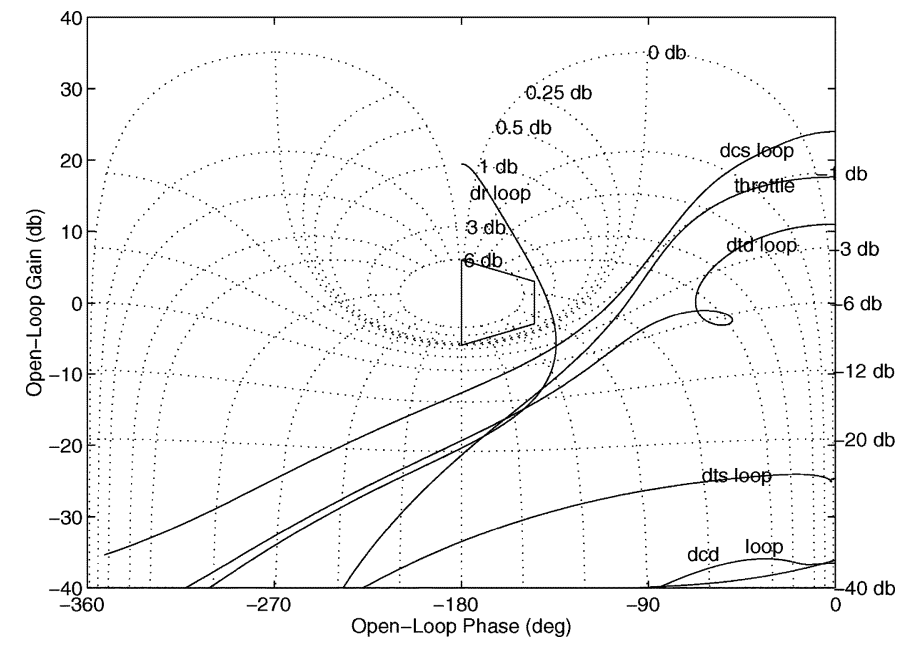

Fig. 6. Open-loop Nichols plots of the present controller in the presence of parametric uncertainties with a flight condition at $\mathrm{M}=0.24$. The trapezoid denotes the gain-phase exclusion region.

Table IV lists the results on whether the Nichols plot for each single-loop frequency response avoids or enters the required exclusion zone. The Nichols plots for the $H_{\infty}$ design are available
TABLE IV

ANALYSis of EACH CONTROLLER'S OPEN LOOP NiCHOLS Plots ENTERING/AVOIDING THE GAIN-PHASE EXClusion ZONE, WHERE * Denotes That THE Nichols Plots For the $H_{\infty}$ Design ARE ONLY FOR THE NOMINAL CASE

\begin{tabular}{l|l|l|l|l|l|l}
\hline Loop & LQ & $H_{\infty} *$ & $\mu-1$ & NDI & RIDE & Present \\
\hline$\delta_{T S}$ & Enter & Avoid & Avoid & Avoid & Avoid & Avoid \\
\hline$\delta_{T D}$ & Avoid & Avoid & Avoid & Avoid & Avoid & Avoid \\
\hline$\delta_{C S}$ & Avoid & Avoid & Enter & Avoid & - & Avoid \\
\hline$\delta_{C D}$ & Avoid & Avoid & Avoid & Avoid & - & Avoid \\
\hline$\delta_{R}$ & Avoid & Avoid & Avoid & Avoid & Enter & Avoid \\
\hline$\delta_{T H}$ & Avoid & Avoid & Avoid & Avoid & - & Avoid \\
\hline
\end{tabular}

only for the nominal case. There are no results shown for the linear frequency analysis for the second $\mu$-synthesis. For the NDI/LQ design, Nichols plots are obtained by applying only the linear-quadratic feedback control, without using the nonlinear-dynamic-inversion feedforward controller. The RIDE de- 


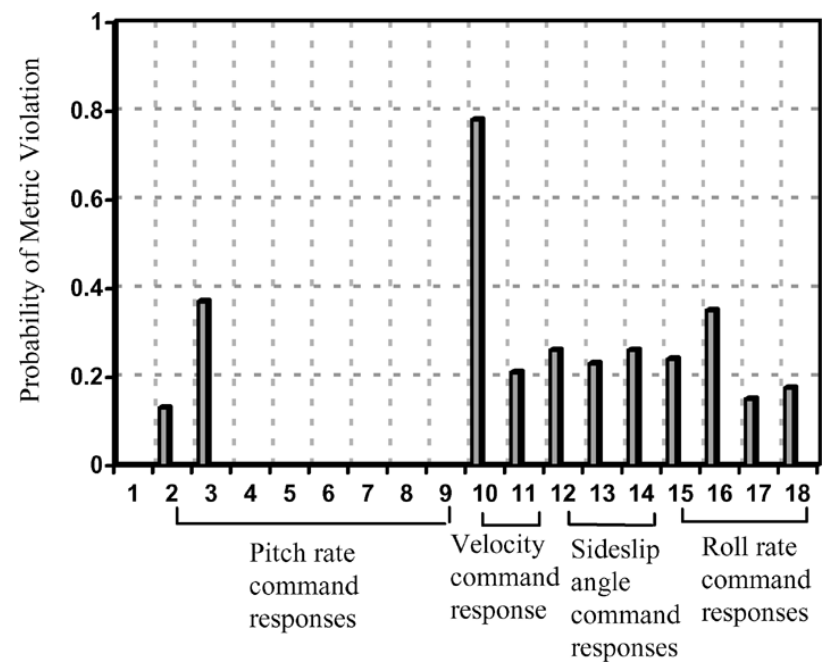

Fig. 7. Robustness profile of the present controller for the HIRM challenge.

sign does not use symmetrical and differential canard deflections as control inputs, and results for the thrust loop are not shown in the paper. Table IV demonstrates that for each of the controllers except the NDI/LQ and $H_{\infty}$ (lack of robustness information) in the GARTEUR competition, one loop's linear frequency response cannot satisfy the robustness criteria. We conclude that the nonlinear controller of this paper shows better performance robustness than the earlier designs as portrayed by linear frequency analysis.

Linear frequency analysis is inadequate for evaluating nonlinear dynamic systems and nonlinear control laws. Furthermore, a single set uncertainty that is not proved to be the worst case for the parametric uncertainties is not enough to quantify system robustness. In the next section, the stochastic robustness of the present controller is analyzed for nonlinear time responses at different flight conditions.

\section{Robustness ANALYsis of PRESENT CONTROLLER}

Two thousand Monte Carlo evaluations of the present design with controller parameters in (51) give the probabilistic robustness profile in Fig. 7. The confidence interval for each probability is not shown due to space limitations and can be found in [22]. In the Monte Carlo simulations, random number generators with uniform distributions provide the possible values of the system uncertain parameters. The design cost equals 1.14. The control system has a zero probability of instability (Metric 1) with a $95 \%$ confidence interval of $(0,0.0018)$. For the pitch-rate command response at $\mathrm{M}=0.2$, adding the angle-of-attack limiter causes transients in pitch rate; therefore, the settling-time specification is not evaluated. The pitch-rate command response at $\mathrm{M}=0.3$ is quite good, with low probability of excess settling time (Metric 2, $\left.I_{3 q_{-q T s}}\right)$. The probability of violating settling-time condition at $\mathrm{M}=0.5$ (Metric 3, $I_{5 q_{-} q T s}$ ) is more than double the probability at $\mathrm{M}=0.3$. It is within expectation because $\mathrm{M}=0.2$ and 0.5 represent edge-of-the-envelope flight conditions, and $\mathrm{M}=0.3$ represents a nominal flight condition within the envelope. The probabilities of exceeding angle-of-attack and normal-acceleration limits in pitch-rate command responses equal zero (Metrics 4-9) for all flight conditions with 95\% confidence intervals

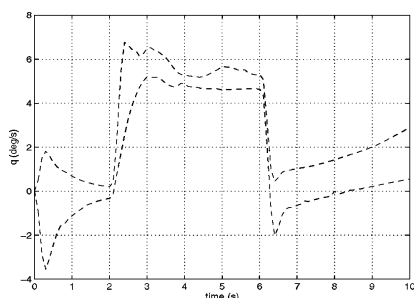

(a)

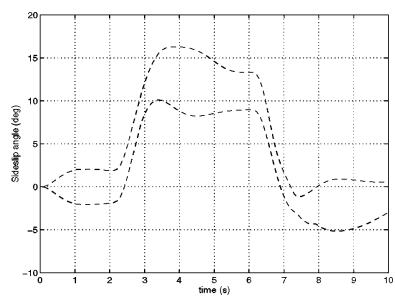

(b)

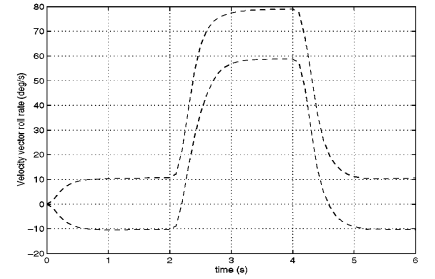

(c)

Fig. 8. (a) Stochastic time-response envelopes for the pitch rate command at $\mathrm{M}=0.5$. (b) Stochastic time-response envelopes for the sideslip angle command at $\mathrm{M}=0.3$. (c) Stochastic time-response envelopes for the roll rate command at $\mathrm{M}=0.3$.

of $(0,0.0018)$. Fig. 7 shows that the probability of exceeding settling time for the velocity-command response is relatively high (Metric 10, $I_{3 V_{-} V T s}$ ), which is caused by the uncertainties in yawing moments and derivatives. The probability of pitch-rate coupling for velocity command is low (Metric $11, I_{3 V_{-} q t}$ ). The performance robustness for sideslip-angle command responses is fine for each flight condition. The probabilities of violating settling time condition are about 20\% (Metrics 12-14). For roll-rate command responses, there are about $30 \%$ probability of excess settling time (Metrics 15-16) and less than 20\% probability of pitch-rate coupling for all flight conditions (Metrics 17-18).

Stochastic time-response envelopes for pitch-rate command at $\mathrm{M}=0.5$, sideslip-angle command at $\mathrm{M}=0.3$, roll-rate command at $\mathrm{M}=0.5$ are plotted in Fig. 8. The envelopes portray the extreme values obtained in one hundred Monte Carlo simulations. The stochastic response envelopes give qualitative information on how parameter uncertainties affect system responses. In each plot, the input is applied at $t=2 \mathrm{~s}$. The transients before the command input are artifacts of the simulation, caused by the off-trim condition that results from parametric uncertainties. The plots show that the controller has good performance robustness.

\section{EFFects on Robustness PRofile by Changing WEIGHTS IN THE ROBUSTNESS COST FUNCTION}

Tradeoffs between satisfying different aspects of robustness can be balanced through changing the weights in the robustness cost function. In this section, the controller structure is unchanged, and the weights for pitch-rate settling-time metric $I_{5 q_{-} q T s}$, roll-rate settling-time metrics $I_{3 p \_p T s}$, and $I_{5 p-p T s}$ are increased to 10 . The new design based on the cost function with modified weights is obtained as

$\boldsymbol{d}=\{0.7529,0.6514,0.8099,0.5753$

$4.95,1.233,2.951,4.165,3.51\}$. 


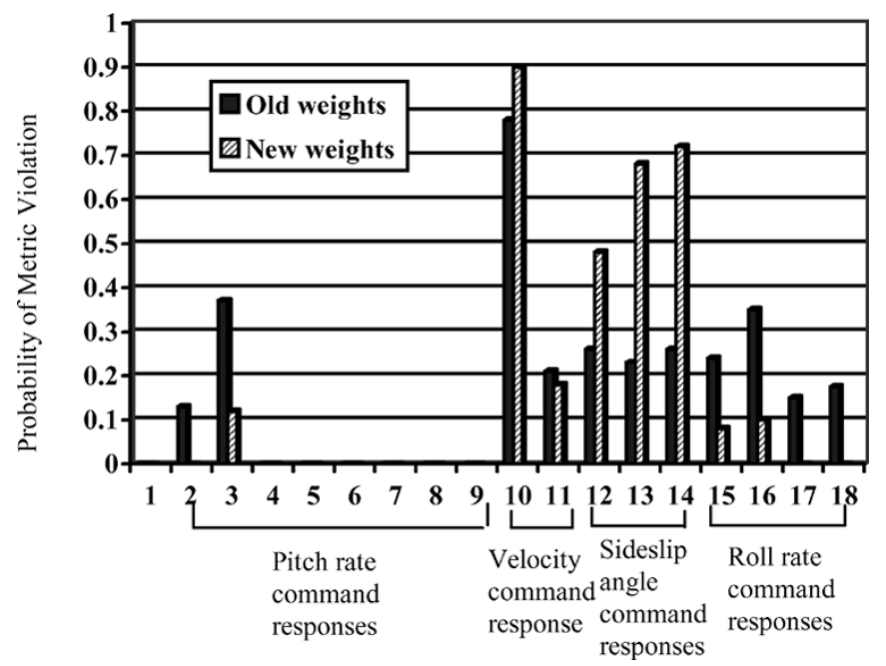

Fig. 9. Comparison of the robustness profiles of two designs with different weights in the robustness cost function.

Fig. 9 shows the variations in the robustness profile of designs due to different weights in the robustness cost function. In Fig. 9, solid bars represent the probabilities of violating design metrics for the design in (51), and striped bars denote the probabilities for the design in (52). Fig. 9 shows that the probabilities of violating $I_{5 q_{-q T s}}, I_{3 p-p T s}$, and $I_{5 p-p T s}$ (Metrics 3, 15, and 16) have decreased by almost two thirds. The probability of violating $I_{3 q_{-} q T s}$ (Metric 2), and the probabilities of violating $I_{3 p_{-} q t}$ and $I_{5 p_{-} q t}$ (Metrics 17-18) have fallen to zero. However, the improvement in robustness for these metrics is achieved at the expense of increasing the probability of violating some other metrics. It is shown that the probabilities of violating requirements in sideslip-angle command responses (Metrics 12-14) are doubled, and the probability of violating the settling-time requirement in the velocity command response (Metric 10) has increased, too.

This comparison illustrates the limitations of redesign within a fixed controller structure. Changing cost function weights can improve specific responses, but it may do so at the expense of degrading the robustness of other responses. Comparing the original design vector (51) with the revised design vector (52), we see that the improved pitch and roll-rate responses led to higher airspeed and sideslip-angle damping, lower airspeed bandwidth, and stiffer yaw rate response. Further improvements would require revisions to the specified structures for slow and fast controllers.

\section{COMPutational Issues}

Numerical search and Monte Carlo simulation are computationally intensive processes. The design procedure uses a GA to search over a probabilistic cost space. Each point in the space is derived from 100 Monte Carlo evaluations of a specific set of control design parameters, and a GA search uses 1000 point evaluations; therefore, there are $10^{5}$ function evaluations. The required number of Monte Carlo simulations for each controller could be determined dynamically as addressed in [15], reducing the number of function evaluations. Furthermore, as suggested by [19], it might even be feasible to use a single sample value of the probability instead of intensive Monte Carlo simulations in the GA search, though it might take relatively more generations for the GA to converge. Since the design approach in this paper implicitly includes extensive evaluation of the system with parametric variations, a great degree of validation is inherent in the control system design that emerges from the process.

\section{CONCLUSION}

The stochastic robust nonlinear control design shows quite good performance and robustness for a highly nonlinear aircraft model including nonlinear actuators and sensors. The model has six degrees of freedom, sixteen state elements, and detailed lookup tables for the aerodynamic coefficients. The flight envelope covers some extreme flight conditions that have large angle of attack. The assessment of maneuvers involves large variations of step command inputs. All these factors make the control design problem highly nonlinear and complicated; however, the stochastic control design technique is straightforward. The success of stochastic robust nonlinear control analysis and design for this HIRM problem demonstrates that the methodology is ready to apply to real nonlinear control design problems.

\section{ACKNOWLEDGMENT}

The authors would like to thank S. Bennani and the Faculty of Aerospace Engineering, Delft University of Technology.

\section{REFERENCES}

[1] E. Muir, "Robust flight control design challenge problem formulation and manual: The high incidence research model (HIRM)," in Robust Flight Control, A Design Challenge (GARTEUR). Berlin, Germany: Springer-Verlag, 1997, vol. 224, Lecture Notes in Control and Information Sciences, pp. 419-443.

[2] S. N. Singh and W. J. Rugh, "Decoupling in a class of nonlinear systems by state variable feedback," ASME J. Dynam. Syst., Meas. Control, pp. 323-329, 1972.

[3] S. N. Singh and A. Schy, "Output feedback nonlinear decoupled control synthesis and observer design for maneuvering aircraft," Int. J. Control, vol. 31, no. 31, pp. 781-806, 1980.

[4] G. Meyer and L. Cicolani, "Application of nonlinear system inverse to automatic flight control designs - System concepts and flight evaluations," in Proc. Theory and Application of Optimal Control in Aerospace Systems, Neuilly-sur-Seire, 1981, AGARD AG251, pp. 10.1-10.29.

[5] G. Meyer, R. Su, and L. R. Hunt, "Application of nonlinear transformations to automatic flight control," Automatica, vol. 20, pp. 103-107, 1984.

[6] P. K. A. Menon, M. E. Badgett, R. A. Walker, and E. L. Duke, "Nonlinear flight test trajectory controllers for aircraft," J. Guid. Control Dyn., vol. 10, no. 1, pp. 67-72, 1987.

[7] S. H. Lane and R. F. Stengel, "Flight control design using nonlinear inverse dynamics," Automatica, vol. 24, no. 4, pp. 471-483, 1988.

[8] P. K. Menon, G. Chatterji, and V. Cheng, "A two-time-scale autopilot for high performance aircraft," AIAA, 91-2674, 1991.

[9] S. S. Mulgund and R. F. Stengel, "Aircraft flight control in wind shear using sequential dynamic inversion," J. Guid. Control Dyn., vol. 18, no. 5, pp. 1084-1091, 1995.

[10] R. F. Stengel and L. R. Ray, "Stochastic robustness of linear time-invariant control systems," IEEE Trans. Automat. Contr., vol. 36, pp. 82-87, Jan. 1991.

[11] C. I. Marrison and R. F. Stengel, "Stochastic robustness synthesis applied to a benchmark control problem," Int. J. Robust Nonlinear Control, vol. 5, no. 1, pp. 13-31, 1995.

[12] Q. Wang and R. F. Stengel, "Searching for robust minimal-order compensators," ASME J. Dynam. Syst., Meas. Control, vol. 123, no. 2, pp. 233-236, 2001.

[13] _ , "Robust nonlinear control of a hypersonic aircraft," J. Guid. Control Dyn., vol. 23, no. 4, pp. 577-585, 2000. 
[14] — , "Robust control of nonlinear systems with parametric uncertainty," Automatica, vol. 38, pp. 1591-1599, 2002.

[15] C. I. Marrison and R. F. Stengel, "Robust control system design using random search and genetic algorithms," IEEE Trans. Automat. Contr. vol. 42, pp. 835-839, Jun. 1997.

[16] T. Motoda, R. F. Stengel, and Y. Miyazawa, "Robust control system design using simulated annealing," J. Guid. Control Dyn., vol. 25, no. 2, pp. 267-274, 2002.

[17] G. Calafiore, F. Dabbene, and R. Tempo, "Randomized algorithms for probabilistic robustness with real and complex structured uncertainty," IEEE Trans. Automat. Contr., vol. 45, pp. 2218-2235, Dec. 2000.

[18] B. T. Polyk and R. Tempo, "Probabilistic robust design with linear quadratic regulators," Syst. Control Lett., vol. 43, pp. 343-353, 2001.

[19] G. Calafiore and B. Polyak, "Fast algorithms for exact and approximate feasibility of robust LMIs," IEEE Trans. Automat. Contr, vol. 46, pp. 1755-1759, Nov. 2001.

[20] Y. Fujisaki, F. Dabbene, and R. Tempo, "Probabilistic robust design of LPV control systems," in Proc. IEEE Conf. Decision Control, 2001, pp. 2019-2024.

[21] B. Etkin, Dynamics of Atmospheric Flight. New York: Wiley, 1972.

[22] Q. Wang, "Stochastic robust control of nonlinear dynamic systems," Ph.D dissertation, Princeton University, Princeton, NJ, 2001.

[23] J. H. Holland, Adaptation in Natural and Artificial Systems. Ann Arbor, MI: Univ. Michigan Press, 1975.

[24] J.-F. Magni, S. Bennani, and J. Terlouw, Robust Flight Control, A Design Challenge (GARTEUR). Berlin, Germany: Springer-Verlag, 1997, vol. 224, Lecture Notes in Control and Information Sciences.

[25] F. Amato, M. Mattei, S. Scala, and L. Verde, "Design via LQ methods," in Robust Flight Control, A Design Challenge (GARTEUR). Berlin, Germany: Springer-Verlag, 1997, vol. 224, Lecture Notes in Control and Information Sciences, pp. 444-463.

[26] G. Papageorgiou, K. Glover, and R. A. Hyde, "The $H_{\infty}$ loop shaping approach," in Robust Flight Control, A Design Challenge (GARTEUR). Berlin, Germany: Springer-Verlag, 1997, vol. 224, Lecture Notes in Control and Information Sciences, pp. 464-483.

[27] K. S. Gunnarsson, "Design of stability augmentation system using $\mu$-synthesis," in Robust Flight Control, A Design Challenge (GARTEUR). Berlin, Germany: Springer-Verlag, 1997, vol. 224, Lecture Notes in Control and Information Sciences, pp. 484-502.

[28] J. A. Markerink, "Design of a robust, scheduled controller using $\mu$-synthesis," in Robust Flight Control, A Design Challenge (GARTEUR). Berlin, Germany: Springer-Verlag, 1997, vol. 224, Lecture Notes in Control and Information Sciences, pp. 503-522.

[29] B. Escande, "Nonlinear dynamic inversion and LQ techniques," in Robust Flight Control, A Design Challenge (GARTEUR). Berlin, Germany: Springer-Verlag, 1997, vol. 224, Lecture Notes in Control and Information Sciences, pp. 523-540.
[30] E. Muir, "The robust inverse dynamics estimation approach," in Robust Flight Control, A Design Challenge (GARTEUR). Berlin, Germany: Springer-Verlag, 1997, vol. 224, Lecture Notes in Control and Information Sciences, pp. 541-563.

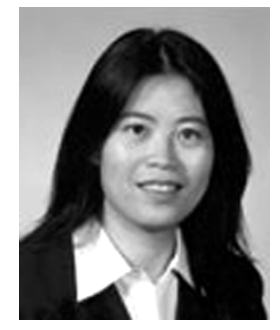

Qian Wang (S'97-M'01) received the B.S. degree in mechanical engineering from Peking University, P.R. China, in 1992, and the M.A. and Ph.D. degrees in mechanical and aerospace engineering from Princeton University, Princeton, NJ, in 1997 and 2001, respectively.

From 2001 to 2002, she did her Postdoctoral research in the Storage System Department, HewlettPackard Laboratories, Palo Alto, CA. There, she filed two U.S. patents with her colleagues and was the coauthor of a finalist paper for the best paper award of the USENIX Conference on File and Storage Technologies (FAST), 2003. In 2002, she became an Assistant Professor in the Mechanical Engineering Department, The Pennsylvania State University, College Park, PA, where she was awarded the James L. Henderson Jr. Memorial Professorship of the College of Engineering. Her research interests are in the fields of robust control, nonlinear control, and optimization, with applications to aerospace, mechanical, and computer systems.

Dr. Wang is a Member of ASME, AIAA, and Sigma-Xi.

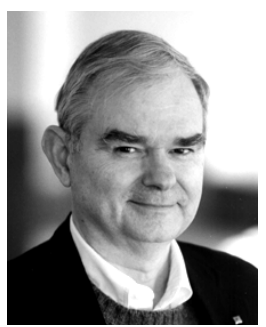

Robert F. Stengel (M'77-SM'83-F'93) received the S.B. degree from Massachusetts Institute of Technology, Cambridge, in 1960 and the M.S.E., M.A., and Ph.D. degrees from Princeton University, Princeton, NJ, in 1965, 1966, and 1968, respectively. $\mathrm{He}$ is a Professor of Mechanical and Aerospace Engineering and former Associate Dean of Engineering and Applied Science, Princeton University. He directs the Laboratory for Control and Automation and the undergraduate program on robotics and intelligent systems. He also has served with The Analytic Sciences Corporation, Charles Stark Draper Laboratory, U.S. Air Force, and NASA. He was a Principal Designer of the Apollo Lunar Module manual control logic and contributed to space-shuttle control system design. $\mathrm{He}$ is the author of Optimal Control And Estimation (New York: Dover, 1994) and has authored or coauthored numerous technical papers and reports.

Dr. Stengel is a Fellow of the American Institute of Aeronautics and Astronautics (AIAA). He received the AIAA Mechanics and Control of Flight Award (2000) and the FAA's first annual Excellence in Aviation Award (1997). 